\title{
Effect of cervical exercises with corrective instructions on neck pain and disability in smartphone addicted users
}

\author{
DOI: https://doi.org/10.5114/pq.2020.102159
}

\author{
Khaled Z. Fouda, ${ }^{1,0}$, Mohammed S. Abdelsalam ${ }^{3}$ \\ ${ }^{1}$ Department of Basic Science for Physical Therapy, Faculty of Physical Therapy, Cairo University, Giza, Egypt \\ 2 Department of Physical Therapy, College of Applied Medical Sciences, Jouf University, Al-Qurayyat, Saudi Arabia \\ ${ }^{3}$ Department of Physical Therapy for Musculoskeletal Disorders and Its Surgery, Faculty of Physical Therapy, \\ Cairo University, Giza, Egypt
}

\section{Abstract}

Introduction. Smartphone use has progressively increased worldwide in the recent few years, with has raised the incidence of musculoskeletal problems related to smartphone overuse. Neck pain is common in subjects practising various occupational and recreational activities. This study investigated the effects of deep cervical flexor muscles exercises with corrective instructions for smartphone use on neck pain and disability in smartphone addicted users.

Methods. Overall, 40 subjects suffering from mechanical neck pain were randomly assigned to group A, who performed deep cervical flexor exercises and were given instructions regarding the correct smartphone use, and to group $B$, who maintained their routine physical activities during the study period, without any further advice. Neck pain intensity was measured with the visual analogue scale, while neck disability was evaluated with the Neck Disability Index.

Results. The dependent $t$-test showed a significant post-treatment reduction $(p<0.001)$ in neck pain and disability in group A, while no significant differences $(p>0.05)$ were found in group B. The independent t-test declared no significant pre-treatment differences $(p>0.05)$ between groups in the measured variables; after treatment, it revealed a significant reduction $(p<0.001)$ in neck pain and disability in group A compared with group B.

Conclusions. Regular practice of deep cervical flexor muscles training in addition to following corrective instructions for smartphone use constitutes an effective therapeutic tool in decreasing neck pain and disability in smartphone addicted users.

Key words: deep cervical flexor, neck pain, disability, smartphone

\section{Introduction}

Neck pain has been reported to be among the most prevalent disorders in the general population; it affects subjects performing either occupational or recreational activities [1]. It is mostly seen in middle-aged people [2]. Moreover, neck pain presents a large economic burden on the health care system [3]. Neck pain is commonly defined by pain location in the area bounded superiorly by the superior nuchal line, inferiorly by an imaginary horizontal line that passes through the tip of the first thoracic spine in frontal plane, and laterally by the lateral borders of the neck [4].

Mechanical neck pain (MNP) is one of the common classes of neck pain identified in the literature [5]. It generally refers to pain in the neck that is related to neck movement or tenderness to palpation of neck muscles [6]. Patients suffering from MNP do not usually present identifiable pathoanatomical causes [7]. Symptoms associated with neurological manifestations, headache of cervical origin, and systematic inflammatory cases are excluded when considering MNP [5].

A high proportion of the world population are currently smartphone users. Unfortunately, drawbacks of prolonged smartphone use are increasingly seen as a major issue. Smartphone overuse has been termed as smartphone addiction, a state defined as an unduly high rate of smartphone use, beyond the subject's control, leading to adverse effects associated with neurotic dependence on the device and its related services [8].
Smartphones are widely used among adolescents. Frequent use that reaches smartphone addiction may result from the availability of advanced models and a wide range of applications in modern versions of the commercially accessible devices $[9,10]$. Among the drawbacks of prolonged smartphone usage is developing neck pain and postural deformities due to the associated postural habits and daily living patterns [11].

Increased musculoskeletal problems related to smartphone overuse have attracted researchers' interest. Among the observed smartphone-related disorders are neck, shoulder, and thumb pain, with greater severity of symptoms reported with prolonged smartphone use [12]. Several faulty postures that include forwards neck, as well as slouched and/or rounded shoulder postures could also be attributed to smartphone overuse [13]. Assuming faulty postures for a prolonged time results in slow deformation due to tissue creep and likely changes in both physical and chemical properties of spinal soft tissues and articulations [14].

Neck pain and disability among smartphone users might be attributed to a habitual repetitive neck flexion posture assumed to turn toward the screen [13]. Repetitive and prolonged neck flexion alters the normal curves of the cervical spine and stresses the cervical spine [14]. In consequence, the skeletal structures surrounding the cervical spine are irritated, which leads to spasm and shortening and probably to a proprioceptive deficit in the cervical region [15]. 
Different physical therapy modalities have been used for MNP treatment, including electrotherapy, myofascial release, stretching exercises, and strengthening exercises [16, 17]. Deep cervical flexors, the longus capitis and longus colli muscles, located anteriorly and anterolaterally to the cervical spine, deep to the sternocleidomastoid muscle, play an important role in stabilizing the cervical spine [18]. In addition, the semispinalis cervicis and cervical multifidus muscles stabilize the cervical spine posteriorly. These muscles form sleeves that function as cervical spine stabilizers against gravity in all positions [19]. Longus colli is of particular importance in maintaining cervical lordosis. Moreover, the longus capitis muscle supports the craniocervical region anteriorly [20].

Therefore, impaired cervical flexor muscles motor control and strength are likely causes of imbalance between neck stabilizers, consequently compromising the proper segmental alignment and posture and resulting in neck pain [21]. So, we hypothesized that deep cervical flexor muscles exercises combined with corrective instructions for smartphone use would have an effect on neck pain and disability in smartphone addicted users. Accordingly, this study was conducted to investigate the impact of deep cervical flexor muscles exercises with corrective instructions for smartphone use on neck pain and disability in smartphone addicted users.

\section{Subjects and methods}

\section{Participants}

Overall, 40 subjects who suffered from self-reported MNP related to prolonged smartphone usage were recruited to participate in the study. They were students at the Faculty of Physical Therapy, Cairo University. Their mean age was 21.71 years, while their mean body mass index was $26.58 \mathrm{~kg} / \mathrm{m}^{2}$. The inclusion criteria were as follows: having used a smartphone for more than 1 year for at least 2 hours per day, complaining of neck pain after using a smartphone, addiction to smartphone in accordance with the smartphone addiction scale (SAS) [22, 23]. The smartphone addiction score was applied to classify excessive smartphone male and female users, with a cut-off point of 31 (out of 60 ) for males and 33 for females [10]. Subjects were excluded if they had a neurological or musculoskeletal disease, vestibular system problems, previous trauma or fracture around the cervical region, or any deformities in the cervical or shoulder regions [22]. Before the study onset, the participants received a complete explanation of the research objectives and procedures.

The study followed a pretest-posttest randomized controlled clinical trial design. Randomization was performed by using random number generator software (Random.org). Two independent groups of 20 numbers each were created from the range of numbers 1-40 without repetitions; a blind draw was carried out to select which set of numbers would represent each of the study groups. Subjects who were found eligible to participate in accordance with the inclusion/exclusion criteria and who signed a consent to participate were asked to select a number in an opaque envelop. In agreement with this concealed selection, each individual was allocated in the group to which their number belonged.

\section{Outcome measures}

\section{Smartphone addiction}

SAS short version, a self-reporting scale, was used to version of SAS was applied. It consists of 10 items. The subjects were asked to record their answers on a 6-point agreedisagree Likert scale (1 - strongly disagree, 6- strongly agree). The scale had been reported to be a valid tool to evaluate smartphone addiction [10]. The internal consistency test result of the Arabic short version SAS showed a good reliability (Cronbach's alpha: 0.87) [24].

\section{Pain}

The visual analogue scale (VAS) was utilized to evaluate pre- and post-treatment pain. VAS is a $10-\mathrm{cm}$ long line, with one end representing 'no pain' and the other standing for 'worst pain ever'. VAS had been reported to be a valid and reliable pain assessment tool [25].

\section{Neck disability}

The Arabic version of Neck Disability Index (NDI) consists of 10 items (50-point index questionnaire). It was used to assess how neck pain and other symptoms manifested during various functional activities. NDI had been reported as a reliable (Cronbach's alpha: 0.89 ) and valid instrument to evaluate self-rated disability in patients with neck pain [26, 27].

\section{Procedures}

Subjects in group A (experimental group) were asked to perform exercises for deep cervical flexor muscles, following the instructions given to them by a therapist during a demonstration session. The participants remained in a crook lying position while holding both hands crossed behind the head to stretch the pectoralis major muscle. They were requested to attach the chin to the neck (chin tuck). They had to gently lift their heads a few centimetres. The subjects were to inhale, maintain the position for 7 seconds, then exhale and relax. The exercises were performed in 3 sets, each set consisted of 10 repetitions for a hold of 7 seconds followed by 10 seconds of rest $[28,29]$. The exercises were applied once daily for 4 weeks.

Furthermore, group A received non-guideline instructions regarding the correct use of a smartphone. These were as follows: (1) Bringing the phone up closer to the eye level, try to minimize bending the neck and keep the head in a neutral position. (2) When you are using the phone for a long period, try to bring a supportive chair with an arm rest. (3) Avoid using the phone to one side of the body with the neck rotated or cradling the phone between the ear and shoulder; it is better to use an ear headphone. (4) Consider taking frequent breaks to move your neck in all directions, and try to limit the device use to a maximum of 20 minutes per session. In turn, subjects in group B (control group) were instructed to maintain their routine physical activities during the period of the study, without any further advice.

\section{Statistical analysis}

SPSS (version 22) for Windows was used to conduct the statistical analysis. Means and standard deviations were reported to present patients' characteristics, as well as the outcome variables. A dependent $t$-test was applied to compare within-group mean values. An independent $t$-test verified whether there were significant between-group differences between the mean values of the measured outcomes. The significance level was set at alpha $<0.05$. 


\section{Ethical approval}

The research related to human use has complied with all the relevant national regulations and institutional policies, has followed the tenets of the Declaration of Helsinki, and has been approved by the Research Ethics Committee of the Faculty of Physical Therapy, Cairo University (approval No.: P.T.REC/012/002506).

\section{Informed consent}

Informed consent has been obtained from all individuals included in this study.

\section{Results}

The independent $t$-test showed no significant differences $(p>0.05)$ in the mean age, weight, height, body mass index, or smartphone usage time per day between the groups, as shown in Table 1.

The most common location of pain was the back of the neck $(47.5 \%)$, followed by side of the neck (30\%) and head $(22.5 \%)$. The disability due to neck pain can be classified in 5 levels; in the current study, the majority of participants (55\%) had a mild disability level, $40 \%$ presented moderate disability, and $5 \%$ experienced no disability.

The dependent $t$-test was used to compare the pre- and post-treatment values in each group. It revealed a statistically significant reduction in pain and disability among the subjects in group $A$, while there were no significant differences $(p>0.05)$ in the outcome measures in group $\mathrm{B}$, as presented in Table 2.

The independent $t$-test declared no significant pre-treatment differences between groups in the measured variables $(p>0.05)$. In turn, post-treatment means revealed a significant reduction $(p<0.001)$ in neck pain as well as neck disability $(p<0.001)$ in group A compared with group $B$, as demonstrated in Table 3.

\section{Discussion}

The number of smartphone users has increased exponentially worldwide over the recent few years [10]. Therefore, the present study was conducted to investigate the effect of deep cervical flexor muscles exercises with corrective instructions for smartphone use on neck pain and disability in smartphone addicted users. The results showed a significant decrease of neck pain and neck disability level after the treatment with deep cervical flexor muscles strengthening exercises accompanied with corrective instructions for smartphone use; in comparison, the non-exercised group maintained their routine physical activities during the period of the study, without any further advice. The findings are in line with observations from previous studies that Wshowed reduced neck pain after deep cervical flexor training [22, 29, 30].

Table 1. Participants' characteristics

\begin{tabular}{|l|c|c|c|}
\hline \multirow{2}{*}{ Variables } & $\begin{array}{c}\text { Group A } \\
\text { (experimental) }\end{array}$ & $\begin{array}{c}\text { Group B } \\
\text { (control) }\end{array}$ & Comparison \\
\cline { 2 - 4 } Age (years) & Mean $\pm S D$ & Mean $\pm S D$ & $p$ \\
\hline Weight $(\mathrm{kg})$ & $21.54 \pm 1.56$ & $21.88 \pm 1.75$ & 0.52 \\
\hline Height $(\mathrm{cm})$ & $76.84 \pm 5.31$ & $77.45 \pm 5.64$ & 0.72 \\
\hline Body mass index $\left(\mathrm{kg} / \mathrm{m}^{2}\right)$ & $170.76 \pm 5.04$ & $169.95 \pm 4.96$ & 0.61 \\
\hline Smartphone usage time per day $(\mathrm{min})$ & $26.36 \pm 1.99$ & $26.81 \pm 2.17$ & 0.49 \\
\hline Smartphone addiction score & $182.69 \pm 4.82$ & $180.32 \pm 4.59$ & 0.11 \\
\hline Sex, male/female $(n)$ & $35.45 \pm 2.25$ & $35.69 \pm 2.14$ & 0.73 \\
\hline
\end{tabular}

Table 2. Differences between mean values of pre- and post-treatment neck pain and disability in each group

\begin{tabular}{|c|c|c|c|c|c|c|}
\hline \multirow{3}{*}{ Variables } & \multicolumn{3}{|c|}{ Group A (experimental) } & \multicolumn{3}{|c|}{ Group B (control) } \\
\hline & Pre & Post & \multirow{2}{*}{$p$} & Pre & Post & \multirow{2}{*}{$p$} \\
\hline & Mean $\pm S D$ & Mean $\pm S D$ & & Mean $\pm S D$ & Mean $\pm S D$ & \\
\hline Pain (VAS) & $4.99 \pm 1.09$ & $2.91 \pm 0.64$ & $<0.001$ & $5.08 \pm 1.12$ & $5.14 \pm 1.13$ & 0.86 \\
\hline Disability (NDI) & $18.15 \pm 2.03$ & $10.95 \pm 1.48$ & $<0.001$ & $17.77 \pm 1.98$ & $17.94 \pm 2.01$ & 0.78 \\
\hline
\end{tabular}

VAS - visual analogue scale, NDI - Neck Disability Index

Table 3. Differences in mean values of pre- and post-treatment neck pain and disability between the groups

\begin{tabular}{|c|c|c|c|c|c|c|}
\hline \multirow{3}{*}{ Variables } & \multicolumn{3}{|c|}{ Pre-treatment } & \multicolumn{3}{|c|}{ Post-treatment } \\
\hline & Group A & Group B & \multirow{2}{*}{$p$} & Group A & Group B & \multirow{2}{*}{$p$} \\
\hline & Mean $\pm S D$ & Mean $\pm S D$ & & Mean $\pm S D$ & Mean $\pm S D$ & \\
\hline Pain (VAS) & $4.99 \pm 1.09$ & $5.08 \pm 1.12$ & 0.79 & $2.91 \pm 0.64$ & $5.14 \pm 1.13$ & $<0.001$ \\
\hline Disability (NDI) & $18.15 \pm 2.03$ & $17.77 \pm 1.98$ & 0.55 & $10.95 \pm 1.48$ & $17.94 \pm 2.01$ & $<0.001$ \\
\hline
\end{tabular}

VAS - visual analogue scale, NDI - Neck Disability Index 
A study conducted by Edmondston et al. [31] revealed that patients suffering from neck pain exhibited low activation of the deep cervical flexors. The authors pointed out that a low-load program focusing especially on the motor control of the deep neck flexors reduced neck pain and headache. Moreover, deep cervical flexors activation with a biofeedback unit has been shown to be beneficial in strengthening the weakened muscles and thereby improving the muscle performance [32].

Previous studies reported a trend for an excessively flexed craniocervical posture in smartphone-addicted teenagers. This excessively flexed posture has been attributed to the relatively small size of smartphone screens, resulting in users focusing their eyes on the screen; thus, smartphone position and size cause significant changes in craniocervical posture and function [23, 33].

The present study comes in accordance with a previous study that clarified the effect of smartphone addiction on neck disability by the presence of a strong positive correlation between neck disability and length of smartphone usage [34]. A positive effect of craniocervical flexion training has been shown in patients with chronic neck pain and forward head posture conditions [35-37].

In the present study, decreased neck pain and disability that occurred in the experimental group could be attributed to increased strength and activation of the deep cervical flexor muscles after training which improved muscle performance [21, 31, 32]. Also, a correction in the cervical angle might have resulted from the deep cervical flexor training [28], which played a role in the improvement observed in the experimental group. Finally, following the corrective smartphone use instructions that were given to the subjects in the experimental group could have decreased the stresses on the cervical spine, leading to neck pain reduction.

Investigators presented an increased cervical angle after deep cervical flexors exercises, which improved the cervical posture and decreased the stress on the cervical spine [28]. Previous studies reported an association between a small cervical angle and symptoms of head, neck, and shoulder discomfort [38]. It is difficult to maintain a proper posture while using a small-screen smartphone [39]. A higher degree of smartphone addiction might lead to a sensory impairment in recognizing neck posture [40]. So, deep cervical flexors training could improve the cervical kinaesthetic sense and therefore neck stability [41].

Furthermore, pain reduction through exercises of the deep cervical flexors may be explained by an increase in endorphins release with exercises and an improvement in neuromuscular control. Muscle contractions stimulate stretch receptors, and afferents from stretch receptors stimulate the release of endogenous opioids and beta-endorphins from the pituitary gland [42].

The results of the current study suggest that the frequent practice of deep cervical flexor strengthening exercises associated with strict application of the corrective smartphone use instructions that were given to the subjects in the experimental group could be beneficial and of a clinical significance in decreasing neck pain and disability among smartphone addicted users.

\section{Limitations}

A small sample size and the lack of control over participants' activities were limitations of this study. Moreover, the subjects were recruited from only one university (Cairo University, Egypt) and it is unlikely that this population could be representative of all Egyptian university students, which leads to problems with generalization.

\section{Conclusions}

A regular practice of deep cervical flexor muscles training in addition to following corrective smartphone use instructions is an effective therapeutic tool that could be helpful in decreasing neck pain and neck disability in smartphone addicted users. Moreover, it might be feasible to include this intervention in the management protocols for neck pain in smartphone addicted users.

\section{Disclosure statement}

No author has any financial interest or received any financial benefit from this research.

\section{Conflict of interest}

The authors state no conflict of interest.

\section{Funding}

This study did not receive any specific grants from funding agencies.

\section{References}

1. Binder Al. Cervical spondylosis and neck pain. BMJ. 2007;334(7592):527-531; doi: 10.1136/bmj.39127.608 299.80.

2. Fejer R, Kyvik KO, Hartvigsen J. The prevalence of neck pain in the world population: a systematic critical review of the literature. Eur Spine J. 2006;15(6):834-848; doi: 10.1007/s00586-004-0864-4.

3. Nagrale AV, Glynn P, Joshi A, Ramteke G. The efficacy of an integrated neuromuscular inhibition technique on upper trapezius trigger points in subjects with non-specific neck pain: a randomized controlled trial. J Man Manip Ther. 2010;18(1):37-43; doi: 10.1179/106698110X125 95770849605.

4. Misailidou V, Malliou P, Beneka A, Karagiannidis A, Godolias G. Assessment of patients with neck pain: a review of definitions, selection criteria, and measurement tools. J Chiropr Med. 2010;9(2):49-59; doi: 10.1016/j.jcm.2010. 03.002 .

5. Cross KM, Kuenze C, Grindstaff TL, Hertel J. Thoracic spine thrust manipulation improves pain, range of motion, and self-reported function in patients with mechanical neck pain: a systematic review. J Orthop Sports Phys Ther. 2011;41(9):633-642; doi: 10.2519/jospt.2011.3670.

6. Young JL, Walker D, Snyder S, Daly K. Thoracic manipulation versus mobilization in patients with mechanical neck pain: a systematic review. J Man Manip Ther. 2014; 22(3):141-153; doi: 10.1179/2042618613Y.0000000043.

7. Blanpied PR, Gross AR, Elliott JM, Devaney LL, Clewley D, Walton DM, et al. Neck pain: revision 2017. J Orthop Sports Phys Ther. 2017;47(7):A1-A83; doi: 10.2519/ jospt.2017.0302.

8. Won-jun L. An exploratory story on addictive use of smartphone: developing SAUS (smartphone addictive use scale). J Converg Inf Technol. 2013;8(12):403-407; doi: 10.4156/jcit.vol8.issue12.49.

9. Kang J-H, Park R-Y, Lee S-J, Kim J-Y, Yoon S-R, Jung K-I. The effect of the forward head posture on postural balance in long time computer based worker. Ann Rehabil Med. 2012;36(1):98-104; doi: 10.5535/arm.2012.36.1.98.

10. Kwon M, Kim D-J, Cho H, Yang S. The smartphone addiction scale: development and validation of a short ver- 
sion for adolescents. PLoS One. 2013;8(12):e83558; doi: 10.1371/journal.pone.0083558.

11. Lee $\mathrm{H}-\mathrm{j}$. Neck pain and functioning in daily activities associated with smartphone usage. J Kor Phys Ther. 2016;28(3):183-188; doi: 10.18857/jkpt.2016.28.3.183.

12. Lee $\mathrm{S}$, Kang $\mathrm{H}$, Shin $\mathrm{G}$. Head flexion angle while using a smartphone. Ergonomics. 2015;58(2):220-226; doi: 10.1080/00140139.2014.967311.

13. Yoo W-g, Yi C-h, Kim M-h. Effects of a proximity-sensing feedback chair on head, shoulder, and trunk postures when working at a visual display terminal. J Occup Rehabil. 2006;16(4):631-637; doi: 10.1007/s10926-0069059-7.

14. Fredriksson K, Alfredsson L, Ahlberg G, Josephson M, Kilbom A, Wigaeus Hjelm E, et al. Work environment and neck and shoulder pain: the influence of exposure time. Results from a population based case-control study. Occup Environ Med. 2002;59(3);182-188; doi: 10.1136/ oem.59.3.182.

15. Yip CHT, Chiu TTW, Poon ATK. The relationship between head posture and severity and disability of patients with neck pain. Man Ther. 2008;13(2):148-154; doi: 10.1016/ j.math.2006.11.002.

16. El-Gendy MH, Lasheen YR, Rezkalla WKS. Multimodal approach of electrotherapy versus myofascial release in patients with chronic mechanical neck pain: a randomized controlled trial. Physiother Quart. 2019;27(4):6-12; doi: 10.5114/pq.2019.87735.

17. Khalil MA, Alkhozamy H, Fadle S, Hefny AM, Ismail MA. Effect of Mulligan upper cervical manual traction in the treatment of cervicogenic headache: a randomized controlled trial. Physiother Quart. 2019;27(4):13-20; doi: 10.5114/pq.2019.87738.

18. Boyd-Clark LC, Briggs CA, Galea MP. Muscle spindle distribution, morphology, and density in longus colli and multifidus muscles of the cervical spine. Spine. 2002;27(7): 694-701; doi: 10.1097/00007632-200204010-00005.

19. Conley MS, Meyer RA, Bloomberg JJ, Feeback DL, Dudley GA. Noninvasive analysis of human neck muscle function. Spine. 1995;20(23):2505-2512; doi: 10.1097/ 00007632-199512000-00009.

20. Kettler A, Hartwig E, Schultheiss M, Claes L, Wilke H-J. Mechanically simulated muscle forces strongly stabilize intact and injured upper cervical spine specimens. J Biomech. 2002;35(3):339-346; doi: 10.1016/s00219290(01)00206-8.

21. Falla DL, Jull GA, Hodges PW. Patients with neck pain demonstrate reduced electromyographic activity of the deep cervical flexor muscles during performance of the craniocervical flexion test. Spine. 2004;29(19):21082114; doi: 10.1097/01.brs.0000141170.89317.0e.

22. Kong Y-S, Kim Y-M, Shim J-M. The effect of modified cervical exercise on smartphone users with forward head posture. J Phys Ther Sci. 2017;29(2):328-331; doi: 10.1589/jpts.29.328.

23. Kee I-K, Byun J-S, Jung J-K, Choi J-K. The presence of altered craniocervical posture and mobility in smartphone-addicted teenagers with temporomandibular disorders. J Phys Ther Sci. 2016;28(2):339-346; doi: 10.1589/jpts.28.339.

24. Sfendla A, Laita M, Nejjar B, Souirti Z, Touhami AAO, Senhaji M. Reliability of the Arabic Smartphone Addiction Scale and Smartphone Addiction Scale-Short Version in two different Moroccan samples. Cyberpsychol Behav Soc Netw. 2018;21(5):325-332; doi: 10.1089/ cyber.2017.0411.
25. Boonstra AM, Schiphorst Preuper HR, Reneman MF, Posthumus JB, Stewart RE. Reliability and validity of the visual analogue scale for disability in patients with chronic musculoskeletal pain. Int J Rehabil Res. 2008;31(2): 165-169; doi: 10.1097/MRR.0b013e3282fc0f93.

26. Vernon $\mathrm{H}$. The Neck Disability Index: state-of-the-art, 1991-2008. J Manipulative Physiol Ther. 2008;31(7): 491-502; doi: 10.1016/j.jmpt.2008.08.006.

27. Shaheen AAM, Omar MTA, Vernon H. Cross-cultural adaptation, reliability, and validity of the Arabic version of neck disability index in patients with neck pain. Spine. 2013;38(10):E609-E615; doi:10.1097/BRS.0b013e318 28b2d09.

28. Lee NK, Jung SI, Lee DY, Kang KW. Effects of exercise on cervical angle and respiratory function in smartphone users. Osong Public Health Res Perspect. 2017;8(4): 271-274; doi: 10.24171/j.phrp.2017.8.4.07.

29. Kage V, Patel NY, Pai MP. To compare the effects of deep neck flexors strengthening exercise and McKenzie neck exercise in subjects with forward neck posture: a randomised clinical trial. Int J Physiother Res. 2016; 4(2):1451-1458; doi: 10.16965/ijpr.2016.117.

30. Iqbal ZA, Rajan R, Khan SA, Alghadir AH. Effect of deep cervical flexor muscles training using pressure biofeedback on pain and disability of school teachers with neck pain. J Phys Ther Sci. 2013;25(6):657-661; doi: 10.1589/ jpts.25.657.

31. Edmondston $S$, Björnsdóttir $G$, Pálsson $T$, Solgård $H$, Ussing K, Allison $\mathrm{G}$. Endurance and fatigue characteristics of the neck flexor and extensor muscles during isometric tests in patients with postural neck pain. Man Ther. 2011;16(4):332-338; doi: 10.1016/j.math.2010.12.005.

32. Kang DY. Deep cervical flexor training with a pressure biofeedback unit is an effective method for maintaining neck mobility and muscular endurance in college students with forward head posture. J Phys Ther Sci. 2015; 27(10):3207-3210; doi: 10.1589/jpts.27.3207.

33. Lee JI, Song HS. The correlation analysis between hours of smartphone use and neck pain in the Gachon University students (in Korean). Acupuncture. 2014;31(2):99109; doi: 10.13045/acupunct.2014028.

34. Bababekova Y, Rosenfield M, Hue JE, Huang RR. Font size and viewing distance of handheld smart phones. Optom Vis Sci. 2011;88(7):795-797; doi: 10.1097/ OPX.0b013e3182198792.

35. Falla D, Jull G, Russell T, Vicenzino B, Hodges P. Effect of neck exercise on sitting posture in patients with chronic neck pain. Phy Ther. 2007;87(4):408-417; doi: 10.2522/ ptj.20060009.

36. Lee K-W, Kim W-H. Effect of thoracic manipulation and deep craniocervical flexor training on pain, mobility, strength, and disability of the neck of patients with chronic nonspecific neck pain: a randomized clinical trial. J Phys Ther Sci. 2016;28(1):175-180; doi: 10.1589/jpts.28.175.

37. Gupta BD, Aggarwal S, Gupta B, Gupta M, Gupta N. Effect of deep cervical flexor training vs. conventional isometric training on forward head posture, pain, neck disability index in dentists suffering from chronic neck pain. J Clin Diagn Res. 2013;7(10):2261-2264; doi: 10.7860/ JCDR/2013/6072.3487.

38. Lau HMC, Chiu TTW, Lam T-H. Measurement of craniovertebral angle with electronic head posture instrument: criterion validity. J Rehabil Res Dev. 2010;47(9):911918; doi: 10.1682/jrrd.2010.01.0001.

39. Berolo S, Wells RP, Amick BC $3^{\text {rd }}$. Musculoskeletal symptoms among mobile hand-held device users and their 
relationship to device use: a preliminary study in a Canadian university population. Appl Ergon. 2011;42(2):371378; doi: 10.1016/j.apergo.2010.08.010.

40. Lee S-Y, Lee D-H, Han S-K. The effects of posture on neck flexion angle while using a smartphone according to duration. J Korean Soc Phys Med. 2016;11(3):35-39; doi: 10.13066/kspm.2016.11.3.35.

41. Jull G, Falla D, Treleaven J, Hodges P, Vicenzino B. Retraining cervical joint position sense: the effect of two exercise regimes. J Orthop Res. 2007;25(3):404-412; doi: 10.1002/jor.20220.

42. O'Leary S, Falla D, Hodges PW, Jull G, Vicenzino B. Specific therapeutic exercise of the neck induces immediate local hypoalgesia. J Pain. 2007;8(11):832-839; doi: 10.1016/j.jpain.2007.05.014. 